Stipendista Ministarstva

Univerzitet u Nišu

DOI: https://doi.org/10.46630/gpsi.18.2019.07

Filozofski fakultet

Departman za psihologiju

Niš, Srbija

\title{
USAMLJENOST U INTERPERSONALNIM ODNOSIMA KAO PREDIKTOR SUBJEKTIVNOG BLAGOSTANJA ${ }^{2}$
}

\begin{abstract}
Apstrakt
Cilj ovog rada je bio da se ispita odnos socijalne usamljenosti, usamljenosti u ljubavi i usamljenosti u porodici sa komponentama subjektivnog blagostanja. Uzorak je prigodan i čini ga 219 ispitanika (78.99\% žena). Starost ispitanika kreće se u rasponu od 18 do 61 godine, a prosečna starost iznosi $25.28(S D=8.14, M O D=23)$. U ovom istraživanju je od instrumenata korišćena Skala socijalne i emocionalne usamljenosti (Social and Emotional Loneliness Scale for Adults; SELSA: diTomasso \& Spinner, 1993). Za operacionalizaciju subjektivnog blagostanja korišćena je skala zadovoljstva životom (SWLS: Diener, Emmons, Larsen, \& Griffin, 1985), kao i PANAS skala (Watson, Clark, \& Tellegan, 1988) za merenje pozitivnog i negativnog afekta. Podaci su obrađivani regresionom analizom, gde su prediktori bile tri vrste usamljenosti dok su kriterijumske varijable bile komponente subjekivnog blagostanja. Rezultati pokazuju da su sva tri modela statistički značajna. Kao značajni prediktori zadovoljstva životom izdvajaju se sve tri vrste usamljenosti (socijalna usamljenost: $\beta=-.40$; usamljenost $\mathrm{u}$ ljubavi: $\beta=-.20$; usamljenost u porodici: $\beta=-.16$ ), i to sve tri sa negativnim predznakom. Kada je u pitanju pozitivan afekat, značajni prediktor ove varijable je socijalna usamljenost $(\beta=-.20)$, sa negativnim predznakom. Kao statistički značajan prediktor negativnog afekta izdvaja se usamljenost u porodici $(\beta=.15)$. Ograničenja ovog istraživanja tiču se pre svega uzorka, odnosno njegove neujednačenosti po polu i po starosti ispitanika. Dakle, na osnovu rezultata možemo da zaključimo da se na osnovu usamljenosti može, u određenoj meri, predvideti subjektivno blagostanje, da usamljenost u najvećoj meri doprinosti nižim nivoima zadovoljstva životom, dok u ograničenoj meri objašnjava ostale dve komponente subjektivnog blagostanja: pozitivan i negativan afekat.
\end{abstract}

Ključne reči: socijalna usamljenost, usamljenost u ljubavi, usamljenost u porodici, subjektivno blagostanje

\footnotetext{
${ }^{1}$ Adresa autora: a.jovancevic-15800@filfak.ni.ac.rs

${ }^{2}$ Rad je nastao u okviru projekta 179002 koji finansira Ministarstvo prosvete, nauke i tehnološkog razvoja Republike Srbije.
} 


\section{Uvod}

Subjektivno blagostanje je koncept za koji istraživači, kao za jedan od ključnih koncepata mentalnog zdravlja danas, pokazuju sve veće interesovanje. Pod pojmom „subjektivno blagostanje” podrazumevamo ono što ljudi najčešće nazivaju srećom ili zadovoljstvom (Diener, Oishi, \& Lucas, 2003). Sama sintagma „subjektivno blagostanje" uvedena je zbog toga što su pojmovi poput sreće ili zadovoljstva zasićeni velikim brojem različitih značenja. Samim tim što je nov, istovremeno i neutralan, ovaj termin daje mogućnost za precizniju definiciju, što sa pojmovima sreće i zadovoljstva nije bilo moguće. Sam Edvard Diner, koji je jedan od najzaslužnijih za popularizaciju ovog termina, kaže da je termin subjektivno blagostanje zapravo sinonim za sreću, samo što je više naučan i manje zbunjujući (Diener \& Scollon, 2003). Shodno tome, i u ovom radu ćemo koristiti oba pojma tretirajući ih kao sinonime. Prema Dinerovom određenju, subjektivno blagostanje predstavlja ,afektivnu i kognitivnu evaluaciju života" (Diener, 2000) i sastoji se iz dve komponente: 1. Kognitivna (dugoročna) komponenta koja se odnosi na globalnu procenu osobe o njenom zadovoljstvu životom. Zadovoljstvo životom ovde je shvaćeno kao jednodimenzionalni konstrukt koji se odnosi na to u kojoj meri je ispitanik zadovoljan životom generalno, odnosno koliko je po njemu njegov život blizak idealnom i slično; 2. Afektivna (kratkoročna) komponenta koju čine: pozitivni afekat i nizak nivo negativnog afekta. Pozitivni afekat podrazumeva učestalo doživljavanje prijatnih emocija, dok se nizak nivo negativnog afekta odnosi na retko doživljavanje neprijatnih emocija.

Slično određenje pojma „subjektivno blagostanje” daje i Rut Vinhoven, sociolog i jedan od istaknutih istraživača u oblasti subjektivnog blagostanja. On takođe sreću smatra sinonimom za subjektivno blagostanje i definiše je kao „,ukupnu ocenu života koja proističe iz dva izvora informacija: kognitivnog poređenja sa standardom dobrog života i afektivnom informacijom o tome kako se neko oseća najvećim delom vremena" (Veenhoven, 2008, str. 45). Subjektivno blagostanje zauzima istaknuto mesto u savremenim modelima mentalnog zdravlja (Keyes, 2006; Vaillant, 2003), a interesantan i značajan pokazatelj važnosti koja se pridaje subjektivnom blagostanju jeste podatak da određene zemlje pribegavaju osnivanju ministarstva za sreću, koje za cilj ima povećanje subjektivnog blagostanja stanovnika (na primer Ujedinjeni Arapski Emirati). Određenje pojma sreća je veoma bitno i za izbor načina njegovog merenja. Pa su tako neki autori pre Dinera (Gurin, Veroff, \& Feld, 1960, prema Costa $\&$ McCrae, 1980) ispitivali sreću na najjednostavniji mogući način. Oni su prosto pitali ispitanike koliko su srećni. Vidimo da se ovakvo merenje sreće koncentriše na onaj deo subjektivnog blagostanja koji je Diner odredio kao njegov afektivni deo. S druge strane, drugi autori (Campbell, Converse, \& Rodgers, 1976, prema Costa \& McCrae, 1980) su se u svom merenju sreće više skoncentrisali na zadovoljstvo osobe različitim aspektima njenog života, odnosno na komponentu subjektivnog blagostanja koju je Diner istakao kao kognitivnu komponentu ovog konstrukta.

Određenje subjektivnog blagostanja kojim ćemo se u ovom istraživanju voditi, je i prvo pomenuto određenje, određenje Edvarda Dinera i njegovih saradnika 
(Diener et al., 2003). Razlog za odabir ovog određenja se sastoji u tome što je ovo određenje zapravo prvo potpunije određenje sreće, koje uzima u obzir i afektivnu komponentu sreće (jednostavno koliko je osoba srećna) kao i njenu kognitivnu komponentu (koliko je osoba zadovoljna različitim aspektima svog života). Ovo određenje, dakle, uzima u obzir obe komponente sreće, dok su raniji autori birali ili jednu ili drugu komponentu u svojim istraživanjima.

Važno pitanje kada je u pitanju sreća, a kojim se određeni broj istraživača i bavio, jeste to u kojoj meri ona varira zavisno od okolnosti i protoka vremena. Naime, istraživanja pokazuju da je nivo sreće kod istih individua relativno stabilan tokom dužih vremenskih perioda (Costa, McCrae, \& Zonderman, 1987; Diener \& Larsen, 1984; Diener, Sandvik, Seidlizt, \& Diener, 1993, prema Diener, Oishi, \& Lucas, 2009; Netl, 2015). Tako, na primer, Diner i saradnici (Diener et al., 1993, prema Diener et al., 2009) pokazuju da je nivo sreće kod istih ispitanika stabilan tokom perioda od 10 godina, dok, sa druge strane, Kosta i saradnici (Costa et al., 1987) ukazuju na to da sreća kod ljudi koji žive u ustaljenim životnim uslovima nije ništa mnogo stabilnija od sreće kod ljudi koji žive u promenljivim okolnostima. Osim toga, važan pokazatelj može biti i to što je doživljaj sreće mnogo sličniji kod jednojajčanih nego kod dvojajčanih blizanaca (Lykken \& Tellegen, 1996, prema Netl, 2015). Još jedna zanimljiva ilustracija koja govori u prilog tome da promena životnih okolnosti na bolje ne dovodi i do promene nivoa sreće kod ljudi je i podatak koji navodi Čiksentmihalji (Csikszentmihalyi, 1999) da je procenat ljudi koji se izjašnjavao kao srećan u SAD-u bio 30\%, nezavisno od toga koliko je plata u SAD-u rasla. Podaci pokazuju da nema korelacije između ekonomskog rasta i promene prosečnog subjektivnog blagostanja populacije (Mentus, 2017). Sve ove podatke je važno uzeti u obzir prilikom istraživanja subjektivnog blagostanja, kako bi se razjasnilo da ovaj konstrukt nije toliko subjektivan, već da je postojan i da se, samim tim, može pouzdano povezivati sa nekim drugim konstruktima.

Još jedan konstrukt u ovom istraživanju predstavlja konstrukt socijalnih odnosa, ili preciznije, usamljenost u različitim vrstama socijalnih odnosa (u partnerskom, prijateljskom, porodičnom odnosu). Da bismo razumeli važnost socijalnih odnosa za ljude i njihovo mentalno zdravlje, neophodno je pomenuti Viljema MekDugala i gregarni motiv. Čovekovu potrebu za udruživanjem s drugim ljudima prvi je opisao pomenuti autor i nazvao je gregarni motiv (Mek Dugal, 1923, prema Ognjenović, 2005). Ovaj motiv je MekDugal smatrao urođenim i pripisivao mu opuštajući efekat (Mek Dugal, 1923, prema Ognjenović, 2005). Ukoliko je MekDugalova pretpostavka o težnji ka udruživanju i, posledično, opuštajućem efektu iste tačna, postavlja se pitanje da li je opravdano pretpostaviti da će udruživanje s drugima, posredstvom opuštajućeg efekta koji ostvaruje na ljude, dovesti i do većeg subjektivnog blagostanja. Istraživanja koja su za cilj imala rasvetljavanje odnosa na relaciji kvalitet socijalnih odnosa-subjektivno blagostanje potvrđuju ovu pretpostavku. Pokazalo se da veoma srećni ljudi imaju kvalitetnije romantične veze i bolje druge socijalne odnose nego oni koji su manje srećni (Diener \& Seligman, 2002). Oni daju bolje ocene svojim prijateljskim, romantičnim i porodičnim odnosima nego ljudi koji sebe smatraju veoma nesrećnim. Veoma srećni ljudi, takođe, provode manje vremena sami, a više u društvu (Diener \& Seligman, 2002). U jednom 
istraživanju, ljudi su u slučajnim periodima tokom dana upitani o tome koliko su srećni, pritom pokazalo se da su najsrećniji kada su sa svojim prijateljima, i to više nego kada su sa članovima porodice ili kada su sami (Larson, Mannell, \& Zuzanek, 1986). Takođe se pokazalo da socijalni odnosi ne dovode do veće sreće samo onda kada dobijamo socijalnu podršku, već i kada je pružamo (Brown, Nesse, Vinokur, \& Smith, 2003).

Problem kod navedenih istraživanja ogleda se u tome što su različiti autori na različite načine operacionalizovali socijalnu i emocionalnu usamljenost. U istraživanju Dinera i Selidžmena (Diener \& Seligman, 2002) merena je procena ispitanika o kvalitetu njihovih socijalnih i emocionalnih odnosa, dok je usamljenost merena pitanjem koliko vremena tokom dana ispitanici provode sami, a koliko u društvu. U istraživanju Larsona i saradnika (Larson et al., 1986) ispitanici su u slučajnim periodima tokom dana popunjavali upitnike u kojima su, između ostalog, davali odgovore i na pitanja koliko su u tom trenutku srećni, kao i šta u tom trenutku tačno rade. S obzirom na to da nam nisu bili dostupni tehnički uslovi, kakve su za sprovođenje istraživanja imali Larson i saradnici (Larson et al., 1986), i da, s druge strane, količina vremena koje provodimo sa drugim ljudima kao i broj tih ljudi (način merenja koji su koristili Diner i Selidžmen (Diener \& Seligman, 2002) nisu garancija kvaliteta provedenog vremena, u ovom istraživanju smo se odlučili za uvođenje varijable koja se odnosi na socijalnu i emocionalnu usamljenost. Prema teoriji, usamljenost $\mathrm{u}$ domenu prijateljstva predstavlja konstrukt socijalne usamljenosti, dok usamljenost u domenu porodičnih i ljubavnih odnosa predstavlja emocionalnu usamljenost (Ćubela-Adorić i Nekić, 2006). Ovakva podela usamljenosti potiče od Veisa (Weiss, 1973, prema diTomasso \& Spinner, 1993), a kasnije je potvrđena u radovima Di Tomasa i Spinera (DiTomasso \& Spinner, 1993), naknadno prilagođenom našim područjima od strane Ćubele-Adorić i Nekića (Ćubela-Adorić i Nekić, 2006). Upravo ovim modelom usamljenosti ćemo se i voditi u ovom istraživanju.

Imajući u vidu sve do sada navedeno, u ovom istraživanju fokus će biti na ispitivanju doprinosa socijalne $\mathrm{i}$ emocionalne usamljenosti u predikciji različitih komponenti subjektivnog blagostanja.

\section{Metod}

\section{Uzorak i procedura}

Uzorak je prigodan i čini ga 219 ispitanika (78.99\% žena). Starost ispitanika kreće se u rasponu od 18 do 61 godine, a prosečna starost iznosi $25.28(\mathrm{SD}=8.14)$. Kada je u pitanju obrazovanje, u uzorku je bilo učenika srednjih škola (1.4\%), osoba koje su završile srednju školu (6.4\%), najviše je bilo studenata $(63.5 \%)$, onih koji su završili višu školu (3.2\%) i fakultet (10\%), onih koji su završili master studije (11.4\%), kao i nekoliko ispitanika sa doktoratom (4.1\%). Kada je u pitanju posao, od ukupnog uzorka $25.1 \%$ ispitanika je zaposleno, dok ostatak ispitanika ne radi. $\mathrm{Na}$ kraju, kada je u pitanju emocionalno-bračni status ispitanika u uzorku, bilo je najviše ispitanika koji nisu u vezi (49.8\%), potom onih koji su u vezi (34.2\%) a najmanje onih koji su u braku (16\%). 
Podaci su prikupljani online, putem elektronske verzije upitnika. Upitnik je deljen na Fejsbuku, među Fejsbuk prijateljima koji su bili zamoljeni da popune upitnik i proslede ga svojim Fejsbuk prijateljima.

\section{Instrumenti}

Svi korišćeni instrumenti su dostupni i slobodni za korišćenje u istraživačke svrhe.

Skala socijalne i emocionalne usamljenosti (Social and Emotional Loneliness Scale for Adults - SELSA; diTomasso \& Spinner, 1993). Skala je adaptirana za srpsko govorno područje (Ćubela-Adorić i Nekić, 2006). Skala socijalne i emocionalne usamljenosti sastoji se iz tri predmeta merenja: socijalna usamljenost (13 stavki; na primer: „Nemam prijatelja koji deli moja mišljenja”), usamljenost u porodici (11 stavki; na primer: „Nikome u mojoj porodici nije stvarno stalo do mene”) i usamljenost u ljubavi (12 stavki; na primer: „Želeo bih imati ljubavnu vezu koja bi mi pružila više zadovoljstva"). Reč je o sedmostepenoj skali Likertovog tipa, gde je $1=U$ potpunosti se ne slažem, a $7=U$ potpunosti se slažem.

Skala ima zadovoljavajuću pouzdanost merenja, tipa interne konzistencije, na ovom uzorku (Socijalna usamljenost: $\alpha=.92$; usamljenost u porodici: $\alpha=.92$; usamljenost u ljubavi: $\alpha=.94)$. U jednom od prethodnih istraživanja (Ćubela-Adorić i Nekić, 2006), pouzdanost, merena metodom interne konzistencije, bila je sledeća: socijalna usamljenost $\alpha=.88$; usamljenost u porodici $\alpha=.85$ i usamljenost u ljubavi $\alpha=.91$.

Skala zadovoljstva životom (The Satisfaction With Life Scale - SWLS; Diener, Emmons, Larsen, \& Griffin, 1985). Skala zadovoljstva životom koristi se za merenje kognitivne komponente subjektivnog blagostanja. Sastoji se od pet stavki koje mere individualnu evaluaciju zadovoljstva životom generalno. Reč je o sedmostepenoj skali Likertovog tipa, u kojoj je $1=U$ potpunosti se ne slažem, a 7 = U potpunosti se slažem. Primeri stavki: „Zadovoljan/a sam svojim životom”, „Kada bih mogao/la da živim svoj život ponovo, ne bih promenio/la gotovo ništa". Prosek odgovora na pet navedenih pitanja predstavlja ukupni skor zadovoljstva životom.

Skala ima zadovoljavajuću pouzdanost interne konzistencije na ovom uzorku $(\alpha=.91)$. U jednom od prethodnih istraživanja na našem govornom području, za čije potrebe je skala i validirana za korišćenje na našim područjima (Vasić, Šarčević i Trogrlić, 2011) pouzdanost tipa interne konzistencije je iznosila $\alpha=.88$.

Inventar za procenu pozitivnog i negativnog afekta (Positive and Negative Affect Schedule - PANAS; Watson, Clark, \& Tellegen, 1988). PANAS skala se odnosi na merenje afektivne komponente subjektivnog blagostanja. Mihić, Novović, Čolović i Smederevac (2014) adaptirali su ovu skalu za korišćenje na našim prostorima. Sastoji se od dvadeset stavki. Deset stavki mere izraženost pozitivnih afekata (npr.: oduševljenje, ponos), dok drugih deset stavki meri izraženost negativnih afekata (npr.: sram, tuga). Instrukcija koju su ispitanici imali pred sobom zahtevala je da odgovaraju na pitanja uzimajući u obzir svoja osećanja u proteklih nedelju dana, tako da su pozitivan i negativan afekat u ovom istraživanju operacionalizovani kao stanje, a ne kao dispozicija ličnosti. U pitanju je petostepena skala Likertovog tipa, gde je $1=$ Veoma malo ili nimalo, a $5=$ U potpunosti. Izraženost pozitivnog afekta dobija se sabiranjem odgovora na stavkama 
koje se odnose na pozitivni afekat. Isto važi i za računanje izraženosti negativnog afekta.

Skala ima zadovoljavajuću pouzdanost, merenu metodom interne konzistencije, na uzorku ovog istraživanja (pozitivni afekat: $\alpha=.85$; negativni afekat: $\alpha=.89$ ). Pouzdanost dobijena na našem uzorku poklapa se sa pouzdanošću o kojoj izveštavaju autori skale (Watson et al., 1988), a koja iznosi između $\alpha=.86 \mathrm{i} \alpha=.90$ za pozitivni afekat i između $\alpha=.84$ i $\alpha=.87$ za negativni afekat.

\section{Metode analize podataka}

Od statističkih analiza primenjena je korelaciona analiza, kao i linearna regresija, i metod Enter, pri čemu su prediktori bili tri vrste usamljenosti, dok su kriterijumske varijable bile komponente subjektivnog blagostanja (pozitivni i negativni afekat kao i zadovoljstvo životom).

\section{Rezultati}

Tabela 1

Pirsonov koeficijent: Korelacija između subjektivnog blagostanja i usamljenosti

\begin{tabular}{lccc}
\hline & $\begin{array}{c}\text { Socijalna } \\
\text { usamljenost }\end{array}$ & $\begin{array}{c}\text { Usamljenost u } \\
\text { ljubavi }\end{array}$ & $\begin{array}{c}\text { Usamljenost u } \\
\text { porodici }\end{array}$ \\
\hline Zadovoljstvo životom & $-.51 * *$ & $-.34 * *$ & $-.34 * *$ \\
Pozitivan afekat & $-.21 * *$ & -.04 & -.11 \\
Negativan afekat & .16 & .07 & $.19 * *$ \\
\hline$* * p<.01$ & & &
\end{tabular}

Iz Tabele 1 vidimo da postoji statistički značajna i negativna korelacija zadovoljstva životom sa sve tri vrste usamljenosti, vidimo takođe da postoji statistički značajna i negativna korelacija između pozitivnog afekta i socijalne usamljenosti, dok statistički značajna i pozitivna korelacija postoji između negativnog afekta i usamljenosti u porodici. Iz upravo izloženih podataka možemo da zaključimo da nigde ne postoje statistički značajne i visoke korelacije, što znači da nema multikolinearnosti i da je time ispunjen uslov za regresionu analizu.

Tabela 2

Socijalna usamljenost, usamljenost u ljubavi i usamljenost u porodici kao prediktori zadovoljstva životom

\begin{tabular}{lllcccc}
\hline & Prediktori & $R$ & $R^{2}$ & $F$ & $\beta$ & $p$ \\
\hline Model & & .57 & .32 & 33.67 & & .000 \\
& Socijalna usamljenost & & & & -.40 & .000 \\
& Usamljenost u ljubavi & & & & -.20 & .001 \\
& Usamljenost u porodici & & & & -.16 & .008 \\
\hline
\end{tabular}


Na osnovu prikazane tabele pre svega možemo da vidimo da je ovaj regresioni model statistički značajan, što znači da sve tri vrste usamljenosti uzete zajedno statistički značajno predviđaju određen procenat varijanse zadovoljstva životom $\left(R^{2}=.32 ; F(3\right.$, $212)=33.67 ; p<.001)$. Na osnovu $R$ koeficijenta vidimo da je korelacija prediktora sa kriterijumom srednja po intenzitetu. Dalje, vidimo da ovaj model objašnjava $32 \%$ varijanse zadovoljstva životom, na osnovu koeficijenta $R^{2}$. Takođe, na osnovu $\beta$ vrednosti prediktora, vidimo da je socijalna usamljenost najbolji prediktor zadovoljstva životom.

Tabela 3

Socijalna usamljenost, usamljenost u ljubavi i usamljenost u porodici kao prediktori pozitivnog afekta

\begin{tabular}{lllcrcc}
\hline & Prediktori & $R$ & $R^{2}$ & $F$ & $\beta$ & $p$ \\
\hline \multirow{4}{*}{ Model } & .21 & .04 & 3.27 & & .022 \\
& Socijalna usamljenost & & & & -.20 & .008 \\
& Usamljenost u ljubavi & & & & .02 & .780 \\
& Usamljenost u porodici & & & & -.04 & .554 \\
\hline
\end{tabular}

Na osnovu prikazane tabele pre svega možemo da vidimo da je ovaj regresioni model statistički značajan, što znači da sve tri vrste usamljenosti uzete zajedno statistički značajno predviđaju određen procenat varijanse pozitivnog afekta $\left(R^{2}=\right.$ $.04 ; F(3,212)=3.27 ; p<.05)$, ali tek na liberalnijem nivou značajnosti. Na osnovu $R$ koeficijenta vidimo da je korelacija prediktora sa kriterijumom niska po intenzitetu. Dalje, vidimo da ovaj model objašnjava $4 \%$ varijanse pozitivnog afekta, na osnovu koeficijenta $R^{2}$. Takođe, na osnovu $\beta$ vrednosti prediktora, vidimo da je socijalna usamljenost najbolji prediktor pozitivnog afekta, kao i jedini statistički značajan.

Tabela 4

Socijalna usamljenost, usamljenost u ljubavi i usamljenost u porodici kao prediktori negativnog afekta

\begin{tabular}{lllllll}
\hline & Prediktori & $R$ & $R^{2}$ & $F$ & $\beta$ & $p$ \\
\hline \multirow{4}{*}{ Model } & & .22 & .05 & 3.43 & & .018 \\
& Socijalna usamljenost & & & & .11 & .142 \\
& Usamljenost u ljubavi & & & & .00 & .952 \\
& Usamljenost u porodici & & & & .15 & .040 \\
\hline
\end{tabular}

Na osnovu prikazane tabele pre svega možemo da vidimo da je ovaj regresioni model statistički značajan, što znači da sve tri vrste usamljenosti uzete zajedno statistički značajno predviđaju određen procenat varijanse negativnog afekta $\left(R^{2}=\right.$ $.05 ; F(3,212)=3.43 ; p<.05)$, ali tek na liberalnijem nivou značajnosti. Na osnovu $R$ koeficijenta vidimo da je korelacija prediktora sa kriterijumom niska po intenzitetu. Dalje, vidimo da ovaj model objašnjava $5 \%$ varijanse pozitivnog afekta, na osnovu koeficijenta $R^{2}$. Takođe, na osnovu $\beta$ vrednosti prediktora, vidimo da je usamljenost u porodici najbolji prediktor negativnog afekta, kao i jedini statistički značajan. 
Statistička snaga za sve modele je veoma dobra i ima vrednost 1 , što znači da zaključke na osnovu ovih rezultata možemo izvlačiti sa visokom pouzdanošću. Kako bi utvrdili statističku snagu zaključka izvedenog iz sprovedenih regresionih analiza, koršćen je program G*Power, verzija 3.1.9.4. konstruisan i predložen od strane Faula i saradnika (Faul, Erdfelder, Buchner, \& Lang, 2009; Faul, Erdfelder, Lang, \& Buchner, 2007).

\section{Diskusija}

Rezultati istraživanja su pokazali da su sve tri vrste usamljenosti značajni prediktori subjektivnog blagostanja, što je u skladu sa nalazima prethodnih istraživanja. Podsećanja radi, pomenućemo da su prethodna istraživanja pokazala da osobe koje imaju visoke nivoe subjektivnog blagostanja imaju kvalitetnije romantične veze i bolje socijalne odnose druge vrste, od onih koji imaju niže nivoe subjektivnog blagostanja. Oni bolje ocenjuju svoje prijateljske, romantične i porodične odnose u odnosu na ljude koji sebe smatraju veoma nesrećnim. Osobe sa visoko izraženim subjektivnim blagostanjem, takođe, provode manje vremena sami, a više u društvu (Diener \& Seligman, 2002).

Iz rezultata istraživanja vidimo da se pokazalo da je socijalna usamljenost najbolji prediktor subjektivnog blagostanja. Ovaj zaključak izvodimo iz toga što je ova vrsta usamljenosti najbolji prediktor zadovoljstva životom, i jedini prediktor pozitivnog afekta. Ovaj rezultat možemo razumeti ukoliko ga povežemo sa nalazima prethodnih radova. Naime, u jednom istraživanju, ljudi su u slučajnim periodima tokom dana upitani o tome koliko su srećni. Pokazalo se da su najsrećniji kada su sa svojim prijateljima, $i$ to više nego onda kada su sa članovima porodice ili kada su sami (Larson et al., 1986). Takođe, pokazalo se da socijalni odnosi ne dovode do veće sreće samo onda kada dobijamo socijalnu podršku, već i kada je pružamo (Brown et al., 2003).

Sva tri prediktora imaju negativnu korelaciju sa zadovoljstvom životom što ukazuje na to da su osobe koje su manje usamljene u porodičnim, prijateljskim i ljubavnim odnosima zadovoljnije svojim životom. Međutim, iz toga što se kao značajni prediktor pozitivnog i negativnog afekta izdvaja samo po jedna vrsta usamljenosti, kao i iz znatno manjeg procenta objašnjene varijanse pozitivnog i negativnog afekta od strane tri vrste usamljenosti, možemo zaključiti da je usamljenost manje relevantna za afektivnu komponentu subjektivnog blagostanja, $\mathrm{tj}$. za pozitivni i negativni afekat, a znatno više za kognitivnu komponentu subjektivnog blagostanja, tj. za zadovoljstvo životom. Ovo bi moglo da znači da za afektivnu komponentu subjektivnog blagostanja nije toliko bitna procena osobe o njenoj usamljenosti, koliko je bitna generalna sklonost osoba doživljavanju pozitivnih odnosno negativnih emocija. Dakle, prethodni radovi pokazuju da su srećniji ljudi takođe i oni koji dalju bolje ocene o porodičnim, prijateljskim i partnerskim vezama (Diener \& Seligman, 2002). Međutim, ovo istraživanje pokazuje preciznije na koje aspekte sreće, tj. subjektivnog blagostanja, socijalni odnosi imaju najveći efekat. Rezultati ovog rada pokazuju da su oni bitniji za zadovoljstvo životom nego za pozitivni i negativni afekat. 
U teorijskom delu smo pomenuli gregarni motiv, kao i to da mu se pripisuje opuštajući efekat (Ognjenović, 2005). Rezultati ovog istraživanju potvrđuju ovu pretpostavku jer pokazuju da su oni ljudi koji imaju bogatije socijalne odnose, odnosno oni koji su manje usamljeni, ujedno i zadovoljniji svojim životom. Sa druge strane, rezultati takođe pokazuju da su socijalni odnosi manje bitni za generalno pozitivno i/ili negativno raspoloženje ljudi. Dakle, za kognitivni aspekt doživljaja osobe da je zadovoljna svojim životom je bitno koliko su njeni odnosi sa ljudima zadovoljavajući, sa druge strane, za generalno pozitivno raspoloženje ispitanika pokazalo se bitnim koliko se osoba oseća zadovoljno u svojim odnosima sa prijateljima, što je u skladu sa nalazima prethodnih radova koji ukazuju na to da su ljudi najsrećniji kada su sa svojim prijateljima, više nego kada su sa članovima porodice ili kada su sami (Larson et al., 1986). Međutim, rezultati takođe ukazuju na to da su za generalno osećanje negativnog afekta, odnosno za neprijatno raspoloženje, od svih vrsta interpersonalnih odnosa najbitniji porodični odnosi, što nije u skladu sa gore pomenutim nalazima, ali ih možemo povezati sa nalazima drugih radova (Atwine, Cantor-Graae, \& Bajunirwe, 2005; Makame, Ani, \& McGregor, 2007). Naime, ovi radovi ukazuju na to da napuštena deca doživljavaju više negativnih emocija od dece koja nisu napuštena.

Svi ovi podaci zajedno ukazuju na to da je za naš kognitivni doživljaj da je naš život dobar bitno da imamo adekvatne i socijalne i partnerske i porodične odnose, pri čemu su socijalni odnosi najbitniji. Sa druge strane, za doživljavanje pozitivnih emocija i pozitivnog raspoloženja, od svih vrsta odnosa ispitivanih u ovom istraživanju pokazali su se bitnim jedino socijalni odnosi. Na kraju, za negativne emocije su, prema podacima ovog istraživanja izgleda bitni jedino porodični odnosi, od različitih vrsta socijalnih odnosa. Izgleda da se podrška porodice ne smatra toliko bitnom onda kada ona postoji, ali je nedostatak ove podrške veoma važan onda kada ga nema i tada on dovodi do negativnog afekta.

\section{Zaključak}

Cilj ovog istraživanja je bio da se ispita doprinos socijalne i emocionalne usamljenosti u predikciji različitih komponenti subjektivnog blagostanja.

Rezultati delimično potvrđuju nalaze prethodnih radova i ukazuju na to da socijalni odnosi zaista jesu bitni za osećanje sreće, ali, pritom, ovi rezultati preciziraju koji odnosi su bitni za koju komponentu sreće, tj. subjektivnog blagostanja ispitanika.

Teorijski značaj ovog istraživanja sastoji se u dubljem upoznavanju faktora koji doprinose osećanju sreće. Praktični značaj može se ogledati u implikacijama za savetodavni rad sa ljudima koji nisu zadovoljni sobom i svojim životom, i koji često doživljavaju negativni afekat. Naime, ovi podaci mogli bi da budu korisni podaci kao dalji podstrek psihoterapeutima i savetodavnim radnicima, koji rade sa svojim klijentima na njihovom poboljšanju kroz rad na pojačavanju i pospešivanju njihove mreže socijalne podrške.

Nedostaci ovog istraživanja se pre svega odnose na uzorak. Naime, iako je statistična snaga svih regresionih modela u ovom istraživanju velika, i usled toga postoji vrlo malo mesta za sumnju u statistički zaključak, ipak je broj muškaraca i žena u uzorku neujednačen 
usled čega ova varijabla može delovati kao konfundirajuća varijabla. Naime, moguće je da postoje polne razlike u pogledu toga koja je vrsta socijalnih veza bitna muškarcima, a koja ženama, kao i u pogledu generalnog nivoa subjektivnog blagostanja. Za neka dalja istraživanja takođe predlažemo uključivanje i starosti kao kontrolne varijable, kao i status veze ispitanika. Dalje, još jedan nedostatak vezan za uzorak se sastoji u tome što je ovo istraživanje sprovedeno samo na populaciji jedne zemlje, a kako istraživanja poput ovog nisu rađena tako često, bilo bi korisnije sprovesti kros-kulturalnu studiju. Kros-kulturarna studija bi bila korisna kako bi mogli da donesemo zaključke o ovim rezultatima, a da oni pritom budu na jednom globalnijem nivou. Osim toga, ovo istraživanje pokreće pitanja o tome koje su vrste socijalnih veza važne za koje aspekte subjektivnog blagostanja. Tako, na primer, na osnovu ovog istraživanja izgleda da su adekvatne socijalne veze najbitnije za doživljaj osobe da je zadovoljna svojim životom, dok su manje bitne za generalno pozitivno ili negativno raspoloženje. Sa druge strane, izgleda da je porodica najbitniji faktor u tome koliko će individua doživljavati neprijatnih emocija, dok su veze sa prijateljima ono što najviše doprinosi doživljavanju pozitivnih emocija. Sve ove implikacije, odnosno pokrenuta pitanja, bi bilo važno ispitati u narednim istraživanjima.

Dakle, iz ovog istraživanja možemo zaključiti da je socijalna mreža individue i te kako bitna za njeno subjektivno blagostanje, kao i to da su odnosi sa prijateljima jedini izdvojeni bitni za prijatno raspoloženje, dok su porodični odnosi izdvojeni kao jedini bitni za neprijatno raspoloženje.

\section{Reference}

Atwine, B., Cantor-Graae, E., \& Bajunirwe, F. (2005). Psychological distress among AIDS orphans in rural Uganda. Social Science \& Medicine, 61(3), 555-564.

Brown, S. L., Nesse, R. M., Vinokur, A. D., \& Smith, D. M. (2003). Providing social support may be more beneficial than receiving it: Results from a prospective study of mortality. Psychological Science, 14(4), 320-327.

Costa, P. T., \& McCrae, R. R. (1980). Influence of extraversion and neuroticism on subjective well-being: happy and unhappy people. Journal of personality and social psychology, 38(4), 668-678.

Costa, P. T., McCrae, R. R., \& Zonderman, A. B. (1987). Environmental and dispositional influences on well-being: Longitudinal follow-up of an American national sample. British journal of Psychology, 78(3), 299-306.

Csikszentmihalyi, M. (1999). If we are so rich, why aren't we happy? American Psychologist, 54(10), 821-827.

Ćubela-Adorić, V. i Nekić, M. (2006). Zbirka psihologijskih skala i upitnika. Zadar: Sveučilište u Zadru.

Diener, E. (2000). Subjective well-being: The science of happiness, and a proposal for a national index. American Psychologist, 55(1), 34-43.

Diener, E., Emmons, R. A., Larsen, R. J., \& Griffin, S. (1985). The satisfaction with life scale. Journal of Personality Assessment, 49(1), 71-77. 
Diener, E., \& Larsen, R. J. (1984). Temporal stability and cross-situational consistency of affective, behavioral, and cognitive responses. Journal of Personality and Social Psychology, 47(4), 871-883.

Diener, E., Lucas, R. E., \& Oishi, S. (2009). Subjective well-being: The science of happiness and life satisfaction. In S. J. Lopez \& C. R. Snyder (Eds), The Oxford Handbook of positive psychology (Second edition, pp. 63-73). New York, NY: Oxford University Press.

Diener, E. \& Scollon, C. (2003). Subjective well-being is desirable, but not the summum bonum. Unpublished manuscript, University of Minnesota interdisciplinary workshop on well-being, Minneapolis, United States.

Diener, E., \& Seligman, M. E. P. (2002). Verry happy people. Psychological Science. 13(1), 81-84.

Diener, E., Oishi, S., \& Lucas, E. R. (2003). Personality, Culture, and Subjective Well-being: Emotional and Cognitive Evaluations of Life. Annual Review of Psychology, 54, 403-425.

diTomasso, E., \& Spinner, B. (1993). The Development and Initial Validation of the Social and Emotional Loneliness Scale for Adults (SELSA). Personality and Individual Differences, 14(1), 127-134.

Faul, F., Erdfelder, E., Buchner, A., \& Lang, A. G. (2009). Statistical power analyses using G*Power 3.1: Tests for correlation and regression analyses. Behavior Research Methods, 41(4), 1149-1160.

Faul, F., Erdfelder, E., Lang, A. G., \& Buchner, A. (2007). G*Power 3: A flexible statistical power analysis program for the social, behavioral, and biomedical sciences. Behavior Research Methods, 39(2), 175-191.

Keyes, C. L. M. (2006). Subjective well-being in mental health and human development research worldwide: An introduction. Social Indicators Research, 77(1), 1-10.

Larson, R., Mannell, R., \& Zuzanek, J. (1986). Daily well-being of older adults with friends and family. Psychology and Aging, 1(2), 117-126.

Makame, V., Ani, C., \& McGregor, S. (2007). Psychological well-being of orphans in Dar El Salaam, Tanzania. Acta Paediatrica, 91(4), 459-465.

Mentus, V. (2017). Povezanost ekonomskog rasta $i$ subjektivnog blagostanja Preispitivanje Isterlinovog paradoksa u slučaju ekonomski razvijenih društava (Neobjavljena doktorska disertacija). Filozofski fakultet, Beograd.

Mihić, L., Novović, Z., Čolović, P., \& Smederevac, S. (2014). Serbian adaptation of the positive and negative affect schedule (PANAS): Its facets and second-order structure. Psihologija, 47(4), 393-414.

Netl, D. (2015). Sreća: Nauka iza vašeg osmeha. Beograd: Centar za promociju nauke.

Ognjenović, P. (2005). Naše namere i osećanja. Beograd: Gutenbergova galaksija.

Vaillant, G. E. (2003). Reviews and overviews: Mental health. American Journal of Psychiatry, 160(8), 1373-1384.

Vasić, A., Šarčević, D. i Trigolić, A. (2011). Zadovoljstvo životom u Srbiji. Primenjena Psihologija, 4(2), 151-177.

Veenhoven, R. (2008). Sociological theories of well-being. In M. Eid \& R. J. Larsen (Eds.), The Science of Subjective Well-Being: A tribute to Ed Diener (pp. 44-61). New York, NY: Guilford Press. 
Watson, D., Clark, L.A., \& Tellegan, A. (1988). Development and validation of brief measures of positive and negative affect: The PANAS scales. Journal of Personality and Social Psychology, 54(6), 1063-1070.

\author{
Ana Jovančević ${ }^{3}$ \\ Scholarship holder of the Ministry of Education \\ University of Niš \\ Faculty of Philosophy \\ Department of Psychology \\ Niš, Serbia
}

\title{
LONELINESS IN INTERPERSONAL RELATIONS AS A PREDICTOR OF SUBJECTIVE WELL-BEING
}

\begin{abstract}
The aim of this paper was to examine the relationship between social loneliness, loneliness in love and loneliness in the family with components of the subjective wellbeing. The sample is conveniente and it consists of 219 respondents ( $78.99 \%$ women). The age of the respondents ranged from 18 to 61 years, with an average age of 25.28 (SD $=8.14, M O D=23)$. In this study, the Social and Emotional Loneliness Scale for Adults (SELSA: diTomasso \& Spinner, 1993) was used from the instruments. A life satisfaction scale (SWLS: Diener, Emmons, Larsen, \& Griffin, 1985) was used to operationalize subjective well-being, as well as a PANAS scale (Watson, Clark, \& Tellegan, 1988) to measure positive and negative affect. The data were processed by regression analysis, where predictors were three types of loneliness while criterion variables were components of subjective well-being. The results show that all three models are statistically significant. Significant predictors of life satisfaction are all three types of loneliness (social loneliness: $\beta=-.40$; loneliness in love: $\beta=-.20$; family loneliness: $\beta=$ -.16), all three with negative correlation. When it comes to positive affect, a significant predictor of this variable is social loneliness $(\beta=-.20)$, with a negative sign. Family loneliness $(\beta=.15)$ stands out as a statistically significant predictor of negative affect. The limitations of this study are primarily related to the sample, ie its gender and age disparity. So, based on the results, we can conclude that, based on loneliness, subjective well-being can be predicted to a certain extent, that loneliness contributes to the lower levels of life satisfaction to a greater extent, while it explains, to a limited extent, the other two components of subjective well-being: positive and negative affect.
\end{abstract}

Keywords: social loneliness, loneliness in love, family loneliness, subjective well-being

Primljeno: 16. 06. 2019.

Primljena korekcija: 04. 09. 2019.

Prihvaćeno za objavljivanje: 07. 09. 2019.

\footnotetext{
${ }^{3}$ Corresponding author email: a.jovancevic-15800@filfak.ni.ac.rs
} 